\title{
Spartan and Sambian Societies: Psychosocial Development Stifling Emotional Empathy and Supporting Violent Behaviors
}

\author{
Gerald H. Katzman* \\ Department of Pediatrics, Wayne State University, USA
}

\begin{abstract}
The male children of the ancient Spartans of Greece and the Sambia of New Guinea are exposed to programmed mental maltreatment and physically abusive practices. Through these exposures and societal narratives enforced by coercion and intimidation, aggressive warriors ready to fight to maintain their engrained desire to dominate or fulfill the military goals of the community are produced. Unfortunately, the indoctrination process appears to suppress the capacity for emotional empathy, further facilitating aggressive impulses that are unimpaired due to the lack of orientation to commonly accepted moral values. The implications of the indoctrinations are discussed with suggestions as to what can be done to promote more desirable traits during growth and development.
\end{abstract}

Keywords: Aggressive impulses, ancient Spartans, New Guinea, programmed mental maltreatment, unimpaired.

\section{INTRODUCTION}

Two types of human mental abilities have been described as forms of empathy $[1,2]$. First, there is cognitive empathy (CE) that refers to mental perspective taking (i.e. the ability to see the world from another person's or society's point of view). Theory of Mind and mentalizing are generally considered to be synonymous with CE. Second, there is emotional empathy (EE) that refers to the vicarious sharing of emotion. The ability to both mentalize and be affected by the state of another or others often leads to compassion. Compassion may be defined as being empathetically connected with others in their suffering and taking action to ease their distress [3]. It will become clear that there is good reason to believe that the ablation of $\mathrm{EE}$ interrupts the process leading to the expression of compassion and may even lead to violent behaviors. Two societies where it appears that $\mathrm{CE}$ developed and EE was largely suppressed are those of the Spartans of Ancient Greece and the Sambia of New Guinea.

As a case is developed to suggest psychological mechanisms for the suppression of emotional empathy in Spartan and Sambian societies, it is clear that such an occurrence is not sufficient alone to explain the resultant violent behaviors. Additional practices in both cultures conditioned the minds of the trained warriors, so that they were ready to do battle at a moment's notice. An understanding of all these practices may be helpful to inform an approach to preventing avoidable acts of aggression in other societies.

\section{THE GROWTH AND DEVELOPMENT OF SPARTANS}

The detailed work of Paul Cartledge [4] provides insight into the institutionalized growth and development of Spartan men and women. The process began at birth with scrutiny by

*Address correspondence to this author at the 31130 Squire Lane, Farmington Hills, Michigan, 48331, USA; Tel: (248) 661 - 6783;

E-mail: GeraldKTZM@aol.com elders as to whether the infant was vigorous enough. In the case of girls the criterion was the future ability to bear strong children. For boys, the consideration was the potential to become great warriors. Those infants deemed to be unfit were left by a hillside to die.

From birth to seven years of age, there is little information, except for the fact that children were reared mainly by slaves (Helots). Mothers were not burdened with domestic chores.

At seven years of age, boys were removed from the homes and enrolled in the compulsory educational system known as the Agog. The boys were placed under the supervision of young adult Spartans and organized into groups. At times, not enough food was provided, so boys might have to steal to curb their hunger. If caught stealing, the boys were beaten. Additionally, boys were often beaten by older children who started fights to help make the younger boys strong. Children were commonly whipped in front of groups of other Spartans, but were not allowed to cry out in pain. An instance is told where a boy did cry out in pain during a brutal physical contest that was a routine part of Spartan training. As a result, the boy's mentor was punished for not properly teaching his charge.

At 12 years of age, every Spartan was expected to receive a young adult warrior as his lover or inspirer. The younger partner was known as the "hearer". The relationship probably was sexual. Most importantly, the inspirer served as a mentor whose job was to instill his younger partner with traits such as physical strength, endurance, pain tolerance and self-discipline.

After 18 years of age, prospective Spartan warriors entered a system of common tents where meals were taken. The main meal was served at night. Torches were not allowed, so Spartans would learn stealthy movement by night. To add to the meals and as a test of bravery, hunting was promoted. The wild boar was a favorite target for this 
additional manhood test, with the usual arms of sword, spear and shield.

Girls also went to school to learn to fight. However, they lived at home and their training was not as harsh as the boys. The girls had a lot of independence, especially since the helots did the domestic work. Girls were involved in sports and physical exercise.

Marriage for women occurred at around twenty years of age and for men in their twenties. Spartan marriage was peculiar in that it involved symbolic rape. Although the groom negotiated with the bride's family, the bride was captured by the groom on the wedding night and delivered to a "bridesmaid". The bridesmaid then shaved the bride's head to the scalp, dressed her in a man's cloak and sandals and laid her down alone on a mattress in the dark. The bridegroom first had dinner at the messes, then would come in, undo the bride's belt, lift her and carry her to the bed. The husband continued to visit his wife at night for some time, since he was involved in activities with the other men during the day.

Women were fairly independent. They owned and tended to their property, as their husbands were often away making war. Their independent and fighting spirit is indicated by a comment one mother made to her son who was going to battle. She urged him to "Return with your shield or on it [4]!" Death could be honored as martyrdom for the state and was second only to victory. Coming back alive and defeated was apparently not an option.

Spartan warriors were purposefully focused on being prepared for war and defending the interests of the state. Line dancing was a common practice to honor the gods and support the team concept necessary in war. During battles, Spartan warriors were arranged in phalanx formation where shields were locked together to protect the fiercely advancing columns.

There was a general and somewhat justified xenophobia in Sparta which was surrounded by potential enemies. The takeover of Helot lands was carried out purportedly due to the need for more food to feed an expanding population. When other states were conquered, Spartan officials often made a pact that these territories would need to supply soldiers if Sparta was attacked. However, Sparta would not be required to come to the aid of the conquered territories should they be threatened.

In order to facilitate their exclusive focus on war making, Spartan warriors were legally banned from engaging in any craft or trade activities. Economically productive activities other than fighting were relegated to another group of subjugated persons, namely the Perioeci. As mentioned previously, the Helots were enslaved to carry out the usual domestic needs, including farming. Moreover, the elders of Sparta made it clear that Spartans were free to oppress the Helots to keep them in check. This oppression went so far as sanctioned murder. Thus, Spartans were engaged in a continual battle to defend Sparta against the perceived enemy without and the enemy within (i.e. Helots).

The organization of Spartan society to produce furious fighters was commented on Aristotle. Aristotle maintained that Spartan education aimed to inculcate only one kind of virtue, martial courage, and therefore tended to turn out "beast-like", specifically wolf-like Spartans [4].

The decline of Sparta is attributed to a number of causes. Generally, Spartan warriors considered hand to hand combat as the only real test of courage. They looked down at arrows as being "women's weapons". They were similarly behind in other technological war advances. So, losses in battle contributed to declining manpower, as did the earthquake of $464 \mathrm{BC}$

\section{THE SAMBIA OF NEW GUINEA}

Unlike the Spartans of Ancient Greece where we need to depend on historical reports, information about the Sambia of the Southeastern Highlands of New Guinea is available first hand from the works of Dr. Gilbert Herdt who spent two years living with these natives [5]. As will become apparent, parallels can be drawn between aspects of Sambian society and those of the Spartans. It should be noted that when Dr. Herdt studied the Sambia, warfare among them had been suppressed by the Australian authorities.

From birth to seven years of age Sambia boys are largely cared for by their mothers. Young children are housed in the family hut where there are separate male and female compartments marked-off by sticks. However, young boys are able to go to their mothers at any time for comfort. Fathers are somewhat aloof to their sons, since they view them as under the influence of female contaminants. Physical discipline for young children is frowned upon by parents. Thus, boys are raised quite permissively. They commonly display temper tantrums. Additionally, boys enjoy games with their age mates and often make fun of various aspects of the men's cult. Rough and tumble games such as mock bow fighting, dirt rock fights and king of the mountain games are encouraged by men. These games in the older boys and young initiates apparently are intended to toughen boys, stimulate rivalries and create dominance among them.

At around seven years of age, multiple sequential initiations are undertaken to socialize boys in batches to an aggressive domineering masculinity that Sambia society aspired to achieve. In the first initiation, boys are separated from their parents, and placed under the supervision of a guardian. A public thrashing ceremony is held where boys of several hamlets are run through a gauntlet of males armed with sticks. The boys are introduced to the "men's secret society." They are housed in a communal men's culthouse. There, they are sleep deprived, suffering forceful awakenings should they doze. Additionally, little food or water is provided for two to three days.

By the third day of initiation, the boys have experienced many terrifying ordeals including two beatings, two thrashings with cassowary quill bones, numerous additional blows, been forcibly nosebleed and rubbed with painful stinging nettles. This ritualized assault represents an abrupt change from their earlier boyhood freedom.

The nose-bleeding ritual is apparently carried out to try and free the male body of female contaminants thought to be related to menstrual and uterine blood. It is apparently quite painful and as one boy said, "I feared they were going to kill me [5]." The boys also say that they feel betrayed and 
abandoned by their parents. They also apparently become mistrustful and uncertain because of the unexpected, serial and frightening assaults.

Initiates are continuously threatened in the cult house. They are threatened with death should they reveal the secrets of homosexuality that are told to them. Also, when older, there is a threat of castration for the commission of adultery.

The myth behind homosexuality is communicated during the early initiations. The Sambia believe that ultimate masculinity and virility can only be achieved by the ingestion of semen. The more semen that is ingested, the greater is the strength (jerungdu) that will develop in the initiate and the more likely that he may grow to become a forceful war leader.

In the cult house, boys are bombarded with many stories that they must keep secret. For example, they are told that the flute they are given to suck is like the penis they will suck to gain strength. They are told semen is like mother's milk; that eliminated blood (from the nose-bleeding) is polluted; that all women are polluting; and that semen ingestion is the only way of gaining strength.

As a result of physical and psychological threats, the initiate has no choice but to submit to these various acts that make him feel dominated. Fellatio performed on a bachelor serves a powerful purpose in incorporating the myth of obtaining jerungdu. The boy's guardian and older initiates persuade him that this act is vital for his masculine growth.

Finally, the initiate loses his childhood name and attire and is given a new name with new social rights and obligations to others. Close supervision takes place to ensure that lessons taught during initiations are continued in daily life.

At around 15 to 18 years of age, Sambia boys become "bachelors" and change their roles to "inserters" in homosexual encounters. They also learn of semen replacement techniques, such as ingesting tree sap. There is the ingrained fear of losing strength through the loss of semen. Marriage and a change to heterosexuality occurs in the late teens or early twenties.

Marriages are interesting, in that they are arranged often by infant betrothal or brother-sister exchanges between families. There is an elaborate marriage ceremony that does take place. Interestingly, females are dressed for the marriage ceremony in bark capes that are usually considered as male attire.

Boys are continually striving with their age mates to emulate war leaders who are revered as great hunters and warriors. Dominance of others is a confirmation of manhood in a boy's eyes and his age mates. Boys who are not aggressive are teased and shamed.

Roles for males and females are clearly defined. Males hunt, climb trees and previously took part in war raids. Females are obedient, and perform the functions of gardening and babysitting. Boys are housed in the men's cult house after initiation until marriage. Girls live in the family hut until marriage.

Before the Australian authorities stopped violent confrontations among the Sambia hamlets, warfare was quite common. Male values seemed to invite these encounters. In a dispute, a man's opponent needed to submit to his wishes. Achieving this dominance was consistent with the ethic of jerungdu and would fulfill the war leader stereotype. Failure to gain submission from an opponent would signify weakness and unmanliness.

Thus, Sambians have a need to view themselves as aggressive, virile males. Their self-image is easily impacted with any perceived challenge to their manhood. As a result of those factors, several dynamics developed that encouraged violent encounters. First, ritualized bow fights using designated, separated open fields developed between certain hamlets, just as a test of courage. Usually, injuries did not occur. However, when they did, retribution and war raids by males of the hamlet whose person was injured were frequently undertaken. Minor insults or hearsay attributed to one hamlet directed against another could also result in war raids carried out with the lethal weapons of clubs and axes. As Herdt stated, "What is difficult to grasp is the personal glory-which is a valued end in itself-of being successful in war. The glory entails something else: a capacity to regard one's opponents as inhuman \& Sambia have an extraordinary ability to think of true enemies as targets divorced from any sense of humane empathy at all [5]." These lethal battles were more likely to occur between distant villages that did not have kinship ties with each other. This distance and the fact that success and killing in war would gain the respect of others as one attained the status of war leader facilitated the violent battles.

A fascinating development occurred in the late 1990s [6, 7]. A potent form of marijuana (Niugini Gold) began to be grown by the tribes of the Eastern Highlands. With the cash the tribesmen obtained from the sale of marijuana, highpowered assault weapons were purchased. As commented in a 2001 publication, "Disputes over fence lines, injuries, insults or women are traditionally settled by raids or ambushes. For as long as anyone can remember, life has been lived on a war footing. Nowadays, however, arguments are increasingly settled with modern weapons [7]." Many fatalities occurred at a level never before seen with traditional fighting using bows and arrows and clubs. Police were not able to control the carnage.

\section{THE MILIEU THAT LEADS TO COMPASSIONATE ACTIONS AND THE CONVERSE}

To understand how Sambian and Spartan societies produced warriors that were motivated to pursue violent acts without much hesitation, it is helpful to review the process by which values are internalized and subsequently expressed. Andrea Hollingsworth [3] described such a process and outlined four conditions that encourage empathy and ultimately lead to a spirituality of compassion. First, there is interpersonal attunement that occurs when human brains "feel felt" by other brains. "Over time, secure, attuned attachments with other persons may enable us to love more and fear less, rendering us progressively more capable of sharing in the suffering of others and increasing the likelihood that we will take action to alleviate their misery [3]." The neurobiology of the process begins with the mirror neurons [8] that allow us to perceive and pattern for ourselves the emotional, sensory and motor states of others. 
Mirror neuron connections through the insula and limbic systems serve to develop integrated circuits involving various brain regions. Second, there is intrapersonal attunement, also referred to as mindfulness. This mindfulness involves noticing, respecting and loving oneself. To be mindful, however, involves an orientation to learned values. Such learning is represented in the prefrontal cortex and hippocampus of the brain. Certain values such as a reverence for the intrinsic worth of human life, a respect for individual differences and resolving conflicts non-violently through discussion are examples of desirable virtues for promoting peaceful human relations. Unfortunately, there are societies where domination, aggressiveness and subjugation of others are the learned "values." Indeed, the societies of the Sambia and the Spartans seem to be examples of this latter orientation, as will be later detailed. Third, there is relational security. "Interpersonal relationships marked by conflict, insecurity, and distrust can cause us to feel threatened, emotionally deregulated and closed off to empathetic connection with others [3]." Fear appears to prevent the development of empathetic relationships. That is why relational security in a group setting with a mutually supportive community provides the atmosphere necessary for developing trusting, empathetic relationships. Lastly, there are shared narratives. It is generally maintained that shared narratives provide the brain with a tool for both emotional and neural integration. On the one hand, narratives have the potential to contribute in a major way to moral development [9]. On the other hand, stories and behaviors transmitted to support a social cognition that values aggression, domination and violence may have an anticipated effect. That effect would be a suppression of emotional empathy and compassion, so as to facilitate unbridled aggressive actions.

\section{THE EARLY YEARS}

Both the Sambia and Spartans have interesting, but only partially understood customs of early child rearing. In the case of the Sambia, the early years are marked by a permissive type of upbringing. The mother is available for comfort, but neither the father nor mother seems to provide expectations for behavior. The only exception to this approach is the fostering of games that promote domination among age mates by the fathers. For the Spartans, little is known about the early years, except for the fact that the caregiving is provided by the Helot slaves. The mothers are involved in games, singing, dancing and managing their property which they were allowed to inherit. Women also had high expectations of the men as reflected in the comment of a mother to her son that he should come back on his shield (i.e. killed), rather than come back from battle alive and defeated. As Cartledge comments, "Of awesomely stern stuff were women made [4]." Thus, Spartan women would seem to have had an authoritarian type relationship with their sons. The Helots, on the other hand, being oppressed and under threat of death for misbehavior, performed their domestic chores, but it is hard to imagine why they would do so enthusiastically. They, however, did have a reputation for "doing a good job [4]." Lastly, the fathers were involved in training for battle or actually away fighting wars much of the time. So, it is unlikely that fathers spent much time with their children, before they entered the Agog.
In summary, it is a fair statement to make that neither the Sambia nor probably the Spartan children were exposed to an authoritative type upbringing in their early years. Authoritative parenting involves close parental communication with children through reasoning [10]. Such reasoning is directed at correcting misbehavior by pointing out the consequences of the actions of children on themselves and others who might be impacted by their actions. Modeling conduct to promote caring behaviors inside and outside the family would usually be an important component of this type of parenting. Lacking the types of attention attributed to authoritative parenting, it is likely that emotional empathy among the Sambia and the Spartan male children was not well developed, when they entered the next phase of their education as seven year olds.

\section{THE ABLATION OF EMOTIONAL EMPATHY}

Both the Spartans' Agog and the Sambias' Men's Cult represented places of ongoing coercion, intimidation and physical and emotional assault that resulted in apparent fear and extreme insecurity among the initiates. The serial initiations among the Sambia and the daily brutal physical exercises among the Spartans took place over a period of years.

Present evidence suggests that repeated exposure to violence results in a desensitization to these occurrences [11, 12]. Additionally, the prolonged exposure to constant threat is known to evoke a state of hyper-responsiveness to actual or assumed external assaults [13]. So the "toxic stress" that Spartan and Sambia youth suffer has a predictable outcome [14]. The "fight or flight" response is called up at a moment's notice [13-16] and is probably facilitated by the learned cultural mores where aggressiveness and domination are most valued. Executive function that would have inhibited immediate aggressive responses has not been developed and therefore no impedance to violent behaviors is present [17-20].

It is likely that the preoccupation of Sambian and Spartan youth with self- preservation through the ordeals to which they were constantly exposed resulted in little opportunity to care about others. Indeed, the challenge was to survive the personal assaults. It is true that a relationship with mentors was developed. For the Sambia, this relationship was designed to reinforce the coercive narratives and mythology of the society. For the Spartans, the mentoring relationship was designed to develop martial courage, aggressiveness and pain tolerance. Neither society seemed to have sensitivity for the welfare of others as an important value. Moreover, both societies attacked youths perceived to not be adhering to societal norms. Shaming of youth by peers and mentors was used by Sambians, whereas beatings served as a mechanism to keep Spartan trainees from straying from the fold. Forced homosexuality was apparently an additional mechanism to promote adherence to societal norms. Nurturing relationships, particularly after seven years of age, were not prominent in either Sambian or Spartan societies. Neither society apparently promoted narratives that dealt with sensitivity to the needs of their fellows. Teamwork was developed, but again, this was specifically for survival in battle and pursuit of domination. There did not seem to be a place where sensitivity to the personal needs of others was 
valued. As a result, there was little possibility for the development of emotional empathy. What emotional empathy might have developed in the early years probably was ablated by the rigors of the Men's Cult of the Sambians and the Agog of the Spartans.

\section{INDOCTRINATION OR "BRAINWASHING" AS APPLIED TO SPARTANS AND SAMBIANS}

The term " brainwashing" had its origin at the time of the Korean War [21]. It can be defined as a forcible indoctrination to induce someone to give up political, social or religious beliefs and attitudes and to accept contrasting regimented ideas. Alternatively, brainwashing can be defined as persuasion by propaganda or salesmanship. Both definitions imply a procedure for "thought reform" where beliefs are changed.

In considering the Sambia and Spartan children, it is unlikely that the societies had to work to change orientations, but rather to provide a totalitarian type of indoctrination to children with little ability to resist. Such an ability to resist would have had to be based on previously inculcated values. So, it seems that youth from the Sambia and Spartans presented minds that were readily malleable by the authoritarian practices and initiations to which they were exposed. They were not hindered by a previous mindset.

Robert Lifton has described themes of thought reform or "Eight Totalist Themes [21]." The first step is that of milieu control where communication is closely supervised. For the Sambia this control is localized in the Men's Hut and for the Spartans in the Agog. The next idea is that of mystic manipulation where patterns of behavior and emotion are evoked. This is accomplished through coercion and repeated physical ordeals. These same intimidating practices lead to obedience to a "demand for purity" that leads to uniform behavior among the initiates. Deviation from such behaviors by the initiates is apparently viewed as much too risky. A "culture of confession" is also operative. Although, as opposed to a situation of thought reform, the participants didn't need to confess to previously held beliefs. Private beliefs, if made known, differing from those of the group were not, of course, accepted and had to be addressed. A fifth theme involves "sacred science," the ideas that dogmas are unchallengeable. An example of such a dogma in the Sambian society was the need to ingest semen to achieve a vibrant adult maleness. For the Spartans, there was the concept that pain should not be acknowledged in the face of physical battery. Lifton's fifth theme deals with "loading the language" to promote through either coercive or more subtle messages what behaviors are acceptable. The sixth theme deals with the primacy of doctrine over person. Where this theme is concerned, the authoritarian and physically threatening Sambian and Spartan societies offered little choice but compliance to their youth. Lastly, there is the "dispensing of existence." As previously mentioned, one Sambian youth actually thought that he was going to be killed by the initiation where blood was drawn from the nose. This practice of being saved from death by one's mentors also encourages compliance to expected behaviors and acceptance of societal narratives.

So, it is easy to see how Lifton's themes of thought reform apply to both the Sambia and the Spartans. Once caught up in such a totalitarian culture, it is unlikely that there would be much consideration for those in a perceived out-group. Thus, Herd's observation that there would not be much concern by the Sambia for the welfare of distant tribes with which they did not have kinship ties is readily understood [22]. Minor disputes or disagreements thus often resulted in violent confrontations. By the same token, the officially sanctioned oppression of the Helots by the Spartans to the point of occasional murder is also brought into focus.

The acceptance of these in-group themes served to ablate any concern for the out-groups that were apparently dehumanized by the ingrained cultural narratives.

\section{BORN TO LOVE OR BORN TO DOMINATE}

In his book The Mindful Brain [23], Siegel refers to mindfulness as a form of intrapersonal attunement, approached with curiosity, openness, acceptance and love (COAL). In both the Sambian and Spartan societies openness and love do not seem to be prime orientations. Rather, the indoctrinated "values" of domination and aggression seem to be paramount. For the Spartans, even marriage starts out with simulated rape. A minor disagreement among Sambians may result rapidly in a lethal confrontation. Where is the acceptance and love here? Clearly, the inability to approach life's occurrences with COAL must mean that there is a deviation from desired intrapersonal attunement, as suggested by Siegel, in Sambian and Spartan societies. Likely, this is again a product of years of exposure to coercive practices that demand compliance to societal norms and teachings for self-preservation. Such practices apparently suppress the development of emotional empathy and compassion, due to the authoritarian upbringing.

Szalavitz and Perry in their book Born to Love [24] agree with Siegel regarding accepted interpersonal relations. However, they explain why empathy is not only essential for promoting positive relationships, but also in danger of being ablated by societal forces. Again, these negative forces include traumatic experiences, lack of trusting relationships in early life and exposure to a peer group that may demand aggressive behaviors for acceptance. As Oliner's work indicates, those persons who had parents that modeled caring behaviors both inside and outside the family were more likely to nurture children who would take significant risk to help others [25]. So, it is quite clear that we are not born to love, but rather caring behaviors must be learned. Emotional empathy can be developed through a process of authoritative child rearing and exposure to subsequent narratives that promote caring behaviors. The coercion, traumatic initiations, sanctioned bullying and societal narratives promoting aggressive dominating behaviors in both Sambian and Spartan societies did not leave much room for the development of emotional empathy.

\section{WHAT HAVE WE LEARNED FROM THE SPARTANS AND THE SAMBIANS?}

Three personality types have been described as the "Dark Triad [26]." First, there is the narcissist who is self-centered, feels entitled to glory and has little empathy. Next, there is the Machiavellian whose ends justify the means. The 
Machiavellian seems to understand what is going on in the minds of others (cognitive empathy) and uses this knowledge to manipulate others without being hindered by morality or emotional empathy, both of which are lacking. Lastly, there is the psychopath who looks at others as an object merely to be used to achieve self-serving goals. A lack of morality and emotional empathy are also characteristic of the psychopath.

It is not too difficult to see how characteristics of the Dark Triad have been instilled in members of the Spartan and Sambian societies. One only needs to picture the Spartan Warriors involved in self-grooming before the famous Battle of Thermopylae where they were greatly outnumbered to see the induced narcissism [4]. Similarly, the Sambian war leader recounting boastfully about his many conquests in hand to hand battle is another example [5]. The use of conquered peoples by the Spartans for help in self-defense without the need to reciprocate is clearly a societal Machiavellian, if not psychopathic characteristic. Infanticide by Spartans clearly underscores the prime goal of the society to raise citizens as necessary components of a war machine. The humanity of those not deemed fit for war is not a consideration. As mentioned previously, the ability of Sambians to deny the humanity of out-group rival tribes and view them as merely objects to conquer is consistent with the concept of psychopathy. Consequently, the ablation of emotional empathy in and the social cognition of Sambian and Spartan societies led to the development of many of the undesirable traits characteristic of the Dark Triad.

\section{OTHER EXAMPLES OF SPARTAN AND SAMBIAN PSYCHODYNAMICS}

The psychodynamics underpinning the development of Spartan and Sambian warriors have been duplicated in many other individuals and societies throughout world history. In fact, a discipline of Psychohistory has been formed [27]. Accordingly, Lloyd de Mause [28] has maintained that "Psychohistory's main discovery is that war and genocide, like homicide and suicide, is a psychopathic disorder that simply does not occur in the absence of early abuse and neglect."

To further underscore the importance of disordered early attachment and abuse in the genesis of psychopathy, it is instructive to review the early childhood history of three of the most ruthless totalitarian leaders of recent times, namely Adolf Hitler, Joseph Stalin and Saddam Hussein. Additionally, it will be noted that elements of the social cognition of the societies to which these leaders belonged supported their eventual violent behaviors as they rose to and assumed their positions of power.

It is stated that Adolf Hitler's father routinely beat him into unconsciousness [29, 30]. Moreover, in the early twentieth century, throughout Germany and Austria beatings routinely occurred in schools [28]. Sexual abuse in schools also was rampant. There was an apparent majority view that "... democracy was undermining the German race by tolerating freedoms that violated every authoritarian precept parents had beaten into their children for centuries [31]." Children were viewed as being sinful and beatings the main vehicle for ensuring a path to acceptable behavior. In this milieu, it is somewhat easier to understand how Hitler became the leader of a group of "willing executioners [32]" who were intent on serving the motherland and removing the "bad self" from their societies by perpetrating the Holocaust. This bad self is thought to have been ingrained in their emotional brains (alter ego) due to suppressed fear and a perceived death wish that they experienced from their parents as children [33]. It is also likely that the anger developed towards parents was projected onto other groups (Jews, handicapped, gypsies etc.) [34], since this was a "socially acceptable" narrative. So, "toxic stress" during youth and societal attitudes seemed to have led Hitler to his psychopathic course emboldened by the narcissism demonstrated by millions chanting "Heil Hitler".

Joseph Stalin was born in Georgia of the Russian Empire to a cobbler father and a mother who was born a serf [35]. Joseph's father became an alcoholic, suffered setbacks in his business and violently abused his wife and child. Joseph had two other siblings who died in infancy. The family moved many times due to economic hardship. The town where Joseph grew up was quite violent including gang warfare, organized street brawls and wrestling tournaments. Joseph frequently was involved in brawls with other children. Joseph's mother wanted him to be a priest, while his father wanted him to be a cobbler. The mother won out and Joseph received a scholarship to seminary. Before entering seminary, Joseph was not only a choirboy, but also the ruthless leader of a street gang. He was notorious for his cruelty and use of unfair tactics. His gang apparently dominated the streets of his town of Gori. While doing well academically at seminary, Joseph began to read revolutionary materials, including the works of Karl Marx. Subsequently, Joseph became an atheist and joined an organization that evolved into the Bolshevik Party that eventually assumed political control of Russia. As the leader of the Communist Party, Stalin instituted several five year plans. These were disastrous and the inefficiency of the resultant food production caused starvation. There was dissent, but the dissenters were eliminated by the "Great Terror" where millions were done away with by the campaign of state-sponsored murder. This campaign demonstrated Stalin's paranoia and psychopathy, as he treated perceived adversaries as objects to be destroyed. There was no news of death and devastation in the countryside allowed. Only news and images that portrayed Stalin in a flattering light were presented. Changing the name of the city of Tsaritsyn to Stalingrad was a further indication of Stalin's hold on power and his narcissism.

Saddam Hussein's mother suffered from severe depression due to the loss of an older brother from cancer and his biologic father who left or died before he was born [36]. Saddam's stepfather Ibrahim Hassan was said to be brutal, a thief and sheepherder. Not only did he abuse Saddam severely, but also sent him to steal chickens and sheep for subsequent sale [36]. At about ten years of age Saddam fled to Baghdad to live with his uncle, Kairallah. Kairallah imbued a hatred of all foreigners into Saddam. A pamphlet that Kairallah composed entitled "Three Whom God Should not Have Created: Persians, Jews and Flies" was republished by Saddam in 1982. As a result of his experiences, Saddam developed a "lifelong pattern: all actions are justified if they are in the service of furthering Saddam Hussein's needs and ambitions [36]." "Commitments and loyalty are a matter of circumstances and 
circumstances change [36]." Consequently, Saddam maintained his power by assassination of those who would even question his decisions. For this reason, Saddam's inner circle was composed of self-seeking servile flatterers who were ruled by fear. This situation further accentuated Saddam's "malignant narcissism" [36] in his behavior and actions. His use of the actual or the threat of execution for disloyalty is clearly a psychopathic characteristic. Innocent human life was not an impediment and "justified" the unbridled pursuit of what was deemed the "exceptionalism of revolutionary needs [36]."

In addition to early abuse and disordered early attachment in manifesting characteristics of the Dark Triad in individuals, the importance of social cognition in furthering violent behavior can be demonstrated in a number of contemporary populations. A segment of the Palestinian population represents a case in point.

To begin with, there is a high incidence of abuse of children among Palestinian families [37]. Palestinian children enter a society, "whose leaders condemn the most vulnerable, its own children, to a lifetime of sociopathic hatred and to the macabre belief that the highest calling in their precious young lives is to wage unremitting war and die a martyr's death [38]." Indoctrination and incitement of children is carried out in the classrooms, camps, TV and radio of the Palestinian Authority. On TV, Jews and Israelis are represented as demonic figures [38]. Moreover, the need to wipe Israel off the map is frequently spoken of by clerics. Additionally, suicide bombers that are developed from the culture of martyrdom are revered and told before they perpetrate their destructive acts that they will be going to paradise. Reimbursement of families for raising a suicide bomber is frequent from various sources [39]. Soccer fields are often named after the suicide bombers and their pictures are often publicly displayed. A strange type of individual narcissism seems to be operative, since the prospective martyr is deluded to think that the ultimate goal in life and bliss in the afterlife will come from fulfilling the role as a shahid (martyr). Taking out innocents that have been dehumanized and demonized through various media, provides another delusion that psychopathically allows the shahid to treat his or her victims as legitimate objects of lethal aggression.

\section{CHARTING A BENEVOLENT COURSE}

Thus, the Sambian, Spartan and other contemporary cultures have demonstrated ways in which persons can be influenced to rapidly resort to violent behaviors, when indoctrinated male or, at times, female members are placed in perceived threatening situations or instances where the military goals of the tribe or state can be served [40]. There could have been another approach. As Miedzian states [41], “... we must move away from an obsolete concept of masculinity focused on toughness, dominance, emotional detachment, callousness toward women and eagerness to fight." It follows then that a system of childrearing that promotes caring behaviors is critical [42-48]. Additionally, narratives that promote particular virtues are needed $[9,49]$. Such moral narratives need to be programmed into the prefrontal cortex. These narratives include a reverence for the value of human life, respect for individual differences, reasoning to effect conflict resolution, among others. What to do in a world where persons with emotional empathy and compassion must interact with persons and societies that display traits similar to many members of Sambian and Spartan cultures is yet to be determined.

\section{CONFLICT OF INTEREST}

The author confirms that this article content has no conflict of interest.

\section{ACKNOWLEDGEMENTS}

Declared none.

\section{REFERENCES}

[1] Smith A. Coginitive empathy and emotional empathy in Hukman behavior and evolution. The Psychol Record 2006; 66: 3-21.

[2] Ahmad A. A neurobiological mapping of theory of mind. Brain Res Rev 2003; 43: 29-40.

[3] Hollingsworth A. Neuroscience and spirituality implications of interpersonal neurobiology for spirituality compassion. Zygon; 2008; 48: 837-60.

[4] Cartledge P. The Spartans woodstock and New York. The Overlook Press: Peter Meyer Publishers Inc. 2003.

[5] Herdt G. The sambia ritual and gender in new guinea. Fort Worth: Harcourt Bruce Jovanovich Inc. The Dryden Press: Saunders College Publishing 1987.

[6] Thursday, April 7, 2011 Gun culture threatens security ahead of 2012 Elections. IRIN; www.pngblogs.com/2011/04/gun-culturethreatens-security-ahead-of.html [Accessed :10/31/2012].

[7] Ware M. Savage Harvest in Papua New Guinea, marijuana brings in not just cash but guns. From highlands to coast, time penetrates the world of growers, warriors, police and traffickers. www.time. com/time/world/article/0,8599,2047527,00.html [Accessed: 10/ 31/2012].

[8] Bastiaansen J, Thioux M, Keysers C. Evidence for mirror neuron systems in emotions. Phil Trans R Soc B 2009; 364: 2391-404.

[9] Vitz P. The use of stories in moral development. Am Psychol 1990; 45: 709-20.

[10] Cherry K. Parenting styles: What they are and why they matter. 2013, Nov 11; Available from: http://psychology.about.com/od/dev elopmentalpsychology/a/parenting.

[11] Rigterink T, Katz L, Hessler D. Domestic violence and longitudinal associations with children's physiological regulation abilities. J Interpers Violence 2010; 25: 1669-83.

[12] Strenziok M, Krueger F, Deshpande G, Lenroot R, Meer E, Grafman J. Fronto-parietal regulation of media violence exposure in adolescents: a Multi-method study. Soc Cog Affect Neurosci 2011; 6: 537-47.

[13] Impact on the physiology of the brain (Adapted from Creating New Possibilities Workshop 4). 2012, Jun 6; Available from: www.asca.org.au/displaycommon.cfm?an=1\&subarticlenbr-194

[14] Stirling J, Amaya-Jackson L. Understanding the behavioral and emotional consequences of child.abuse. Pediatrics 2008; 122: 66773.

[15] Connor DF, Doerfler LA, Volungis AM, Steingard RJ, Melloni RH. Aggressive behavior in abused children. Ann N Y Acad Sci 2003; 1008: 79-90.

[16] Boutwell B, Franklin C, Barnes J, Beaver K. Physical punishment and childhood aggression: The role of gender and geneenvironment interplay. Aggr Behav 2011; 37: 559-68.

[17] McCrory E, Brito S, Sebastian C, Mechelli A, Bird G, Kelly P, Viding E. Heightened neural reactivity to threat in child victims of family violence. Current Biol 2011; 21: R947-8.

[18] Hare T, Casey B. The neurobiology and development of cognitive and affective. Brain Behav 2005; 9: 273-86.

[19] Churchland P. Braintrust. Princeton New Jersey, Princeton University Press 2011.

[20] Bufkin J, Luttrell V. Neuroimaging studies of aggressive and violent behaviour. Trauma viol abus 2005; 6: 176-91.

[21] Taylor K. Brain washing. Oxford New York: Oxford, University Press 2004.

[22] Pettigrew TF, Tropp LR. A meta-analytic test of intergroup contact theory. J Pers Soc Psychol 2006; 90: 751-83. 
[23] Siegel D. The mindful brain. New York: W.W. Norton \& Company Inc 2007.

[24] Szalavitz M, Perry B. Born for love. New York: Harper Collins Publishers 2011

[25] Oliner S, Oliner P. The altruistic personality. New York: Macmill Inc 1992.

[26] Goleman D. Social Intelligence. New York, New York: Bantam Book 2006.

[27] deMause L. The history of childhood. New York: Psychohistory Press 1974.

[28] deMause L. The childhood origins of the holocaust. 2014, Sep 3; Available from: www.psychohistory.com $/ \mathrm{htm} / \mathrm{childhoodHolocaus}$ t.html

[29] Stierlin H. Adolf Hitler: A Family Perspective. New York: Psychohistory Press 1977

[30] Waite R. The psychopathic God: Adolf Hitler. New York: Basic Books 1977.

[31] Mazower M. Dark Continent: Europe's Twentieth Century. New York: Knopf 1999.

[32] Goldhagen D. Hitler's willing executioners: ordinary germans and the holocaust. New York: Knopf 1996.

[33] deMause L. The origins of war in child abuse. Chapter 3: Inst Psych 2010.

[34] Gaylin W. Hatred: The psychological descent into violence. New York: Public Affairs ${ }^{\mathrm{TM}}$ Persus Books Group 2003.

[35] McKinney L. Joseph Stalin, http://history1900s.about.com/people /ss/Stalin 2.htm [Accessed 9/15/2014].

[36] Post J. Explaining Saddam Hussein: a Psychological Profile. www.au.af.mil/au/awc/awcgate/iraq/saddam post.htm [Accessed: $8 / 21 / 2014]$

[37] Khamis V. Child psychological maltreatment in Palestinian Families. Chil Abuse Neglect 2000; 24(8): 1047-59.

[38] Meir-Levi D. Child abuse as public policy in the palestinian authority. Frontpage mag 2011, Sept 13; Available from: http://www.frontpagemag.com/2011/david-meir-levi/child-abuseas-public.

[39] Ben Zion I. PA spends 6\% of its budget paying Palestinians in Israeli jails, families of suicide bombers. The Times of Israel 2012; Sep 3; Available from: www.timesofisrael.com/cash-strapped-paspends-4-5-million-per-month- compensating-security-detainees/

[40] Shirtcliff E, Vitacco M, Gosticha A, Merz J, Zahn-Waxler C. Neurobiolgy of empathy and callousness: Implications for the dvelopment of antisocial behavior. Behav Sci Law 2009; 27: 13771.

[41] Miedzian M. Boys will be boys. New York, New York: Lantern Books 2002.

[42] Miedzian M. Reducing violence by educating for empathy. ON the Issues Magazine May18, 2010; Available from: www.myriammie dzian.com/05_18_10.html.

[43] Fox S, Levitt P, Nelson C. How the timing and quality of early experiences influence the development of brain architecture. Child Develop 2010; 81:28-40.

[44] Shonkoff J, Levitt P. Neuroscience and the future of early childhood policy: Moving from Why to What and How. Neuron 2010; 67: 689-92.

[45] Knudsen E. Sensitive periods in the development of the brain and behavior. J Cogn Neuro 2004; 16: 1412-25.

[46] Shonkoff J. Protecting brains, not s imply stimulating minds. Sci 2011; 333: 982-83.

[47] Luby J, Barch D, Belden A, et al. Suzuki H, Botteron K. Maternal support in early childhood predicts larger Hippocampal volumes at school age. Proc Natl Acad Sci USA 2014. Available from: www.pnas.org/ cgi/doi/10.1073/pnas.1118003109

[48] Garner A, Shonkoff J. Early childhood adversity, toxic stress, and the $r$ ole of the pediatrician: translating developmental science into lifelong health. Pediatrics 2012; 129: e224-31.

[49] Borba M. Building moral intelligence. San Francisco. Jossey-Bass: A Wiley Imprint 2001.

(c) Gerald H. Katzman; Licensee Bentham Open.

This is an open access article licensed under the terms of the Creative Commons Attribution Non-Commercial License (http://creativecommons.org/licenses/by$\mathrm{nc} / 3.0 /$ ) which permits unrestricted, non-commercial use, distribution and reproduction in any medium, provided the work is properly cited. 